\title{
Carbon monoxide-releasing molecule suppresses inflammatory and osteoclastogenic cytokines in nicotine- and lipopolysaccharide-stimulated human periodontal ligament cells via the heme oxygenase- 1 pathway
}

\author{
LING SONG ${ }^{1,2}$, JINGYUAN LI $^{3}$, XIAO YUAN ${ }^{2}$, WEN LIU $^{2}$, ZHENGGANG CHEN $^{2}$, \\ DAWEI GUO ${ }^{2}$, FANG YANG ${ }^{2}$, QINGYUAN GUO ${ }^{2}$ and HUI SONG ${ }^{1}$
}

\author{
${ }^{1}$ Shandong Provincial Key Laboratory of Oral Tissue Regeneration, School of Dentistry, Shandong University, \\ Jinan, Shandong 250012; ${ }^{2}$ Department of Stomatology, Qingdao Municipal Hospital, Qingdao, Shandong 266011; \\ ${ }^{3}$ Department of Oral Mucosal Diseases, School of Dentistry, Shandong University, Jinan, Shandong 250012, P.R. China
}

Received February 20, 2017; Accepted September 5, 2017

DOI: 10.3892/ijmm.2017.3129

\begin{abstract}
Smoking is identified as a risk factor for periodontitis. Carbon monoxide (CO)-releasing molecule-3 (CORM-3) is a compound that has demonstrated anti-inflammatory effects in vitro and in vivo studies. The present study aimed to investigate the effects of CORM-3 on the expression of inflammatory and osteoclastogenic cytokines in human periodontal ligament cells (PDLCs) stimulated by nicotine and lipopolysaccharide (LPS). The cells were pretreated with CORM-3 and then cultured in medium in the presence of nicotine and LPS. The mRNA and protein expression levels of prostaglandin $\mathrm{E}_{2}\left(\mathrm{PGE}_{2}\right)$, cyclooxygenase-2 (COX-2), osteoprotegerin (OPG), receptor activator of nuclear factor- $\mathrm{\kappa B}$ ligand (RANKL) and heme oxygenase-1 (HO-1) were evaluated using reverse transcription-quantitative polymerase chain reaction and western blot analysis. The mRNA and protein expression levels of these cytokines were also evaluated in PDLCs transiently transfected with HO-1 small interfering RNA (siRNA) in response to nicotine and LPS stimulation. CORM-3 attenuated the LPS- and nicotine-induced production of $\mathrm{PGE}_{2}, \mathrm{COX}-2$ and RANKL in human PDLCs by releasing $\mathrm{CO}$, and upregulated the expression of OPG. However, these effects of CORM-3 were abrogated when HO-1 siRNA was transiently transfected into the cells. These results demonstrate that CORM-3 exerts anti-inflammatory and
\end{abstract}

Correspondence to: Professor Hui Song, Shandong Provincial Key Laboratory of Oral Tissue Regeneration, School of Dentistry, Shandong University, 44-1 Wenhua Xilu, Jinan, Shandong 250012, P.R. China

E-mail: songhui@sdu.edu.cn

Key words: lipopolysaccharide, carbon monoxide releasing molecule-3, anti-inflammatory effects, nicotine, periodontal ligament cells, heme oxygenase-1 anti-osteoclastogenic effects on nicotine- and LPS-stimulated human PDLCs via the HO-1 pathway, which suggests its promising potential for use in the treatment of inflammatory periodontal disease.

\section{Introduction}

Periodontitis is a chronic-inflammatory disease with a high incidence, which is initiated by microorganisms in the dental biofilm and leads to the destruction of tooth-supporting tissues and eventual tooth loss $(1,2)$. Periodontal ligament cells (PDLCs), as a type of stem-like cell, play an important role in maintaining the dynamic stability and function of the periodontium (3). Human PDLCs not only function as support cells for the periodontal tissues but also produce inflammatory mediators in response to pathogens and proinflammatory stimuli; therefore, PDLCs are important in the host immune response (3). The response of human PDLCs to inflammatory stimuli is involved in the pathogenesis of chronic periodontitis (4).

Periodontal pathogenic bacteria, such as Porphyromanas gingivalis and Actinobacillus actinomycetemcomitans, are likely to serve major roles in the pathogenesis of periodontitis $(5,6)$. Lipopolysaccharide (LPS), a cell wall component of gram-negative organisms, is also a potent inducer of the proinflammatory response and initiates numerous hostmediated destructive processes (4). Previous studies have shown that when the human PDLCs are stimulated by LPS, the production levels of the inflammatory cytokines cyclooxygenase-2 (COX-2), interleukin-17 (IL)-17, tumor necrosis factor (TNF)- $\alpha$ and receptor activator of nuclear factor- $\kappa B$ ligand (RANKL) are increased (7). COX-2 is the rate-limiting enzyme of prostaglandin $\mathrm{E}_{2}\left(\mathrm{PGE}_{2}\right)$ synthesis (8). High levels of $\mathrm{PGE}_{2}$ are detected in the gingiva and gingival crevicular fluid of patients with periodontal disease (8), and $\mathrm{PGE}_{2}$ expression is associated with bone resorption during the progression of periodontal diseases (8-12). Smoking has been demonstrated to be a risk factor for periodontitis; in tobacco-smoking 
patients with periodontitis, nicotine, a major toxic substance in tobacco, has been detected in the saliva and gingival crevicular fluid (13). Previous studies have shown that nicotine inhibits the attachment and growth of human gingival fibroblasts and human PDLCs, changes the periodontal tissue microcirculation, and increases the absorption of alveolar bone $(13,14)$.

Following the discovery of RANKL and its decoy receptor osteoprotegerin (OPG), it has been hypothesized that the balance of the OPG/RANKL axis is critical in the regulation of osteoclast differentiation and function (15). During the pathological process of periodontitis, these inflammatory cytokines play an important role in the destruction of the alveolar bone; thus, they are regarded as targets for the suppression of inflammation in tobacco-smoking patients with periodontitis.

Heme oxygenase-1 (HO-1), the most responsive of the known induced enzymes, which can be induced to high levels within hours by cytokines, hemoglobin, oxygen, hyperoxia, heat shock, endotoxins, hydrogen peroxide, ultraviolet radiation, heavy metal and nitric oxide (16), has become a focus of medical research. Studies have demonstrated that HO-1 has cell-protective functions $(17,18)$. With heme as its substrate, HO-1 metabolizes and produces carbon monoxide (CO), biliverdin and $\mathrm{Fe}^{2+}(19)$. $\mathrm{CO}$ has been confirmed to serve a notable role in the biological processes of many cells, including the inhibition of cell proliferation and apoptosis, and the suppression of the immune inflammatory response $(20,21)$. CO-releasing molecules (CORMs) are a new class of compounds, typically transition metal carbonyl complexes, that are capable of liberating CO under the appropriate conditions (22). Therefore, CORMs may be of therapeutic interest due to their capacity to modulate ongoing inflammatory reactions by delivering $\mathrm{CO}$ in a controllable fashion (23). In addition, CORMs have been widely used to increase understanding of the biological function of CO $(24,25)$.

Previously, the present research group found that CORM-3 [tricarbonylchloro(glyconato)-ruthenium(II)], which is fully water-soluble, and rapidly liberates $\mathrm{CO}$ when dissolved in physiological solutions, increases $\mathrm{HO}-1$ expression in vascular endothelial cells (26). The previous study also demonstrated that CORM-3 inhibits the expression of adhesion molecules in human gingival fibroblasts costimulated with TNF- $\alpha$ and IL-1 $\beta$. In the present study, human PDLCs were used as an in vitro model to investigate the influence of CORM-3 on COX-2, $\mathrm{PGE}_{2}$, OPG and RANKL expression in cells stimulated with LPS and nicotine. The possible mechanism by which CORM-3 exerts this effect was also investigated.

\section{Materials and methods}

Reagents. CORM-3 was purchased from Sigma-Aldrich (Merck KGaA, Darmstadt, Germany). Dulbecco's modified Eagle's medium (DMEM) was purchased from HyClone (GE Healthcare Life Sciences, Logan, UT, USA); fetal bovine serum (FBS) was purchased from Biological Industries (Kibbutz Beit-Haemek, Israel); 100X Penicillin-Streptomycin Solution and LPS from Escherichia coli were purchased from Beijing Solarbio Science and Technology Co., Ltd. (Beijing, China); nicotine was purchased from Cerilliant Corp. (Round Rock, TX, USA); antibodies against COX-2 (ab62331), OPG (ab73400), RANKL (ab9957) and HO-1 (ab13248) were purchased from Abcam (Cambridge, UK); the antibody against $\mathrm{PGE}_{2}$ (4a-2639R) was purchased from 4A Biotech Co., Ltd. (Beijing, China); glyceraldehyde 3-phosphate dehydrogenase (GAPDH) antibody (10494-1-AP), $\alpha$-tubulin antibody (11224-1-AP) and the secondary antibodies horseradish peroxidase (HRP)-conjugated affinipure goat anti-rabbit IgG $(\mathrm{H}+\mathrm{L})$ (SA00001-2) and HRP-conjugated affinipure goat anti-mouse IgG (H+L) (SA00001-1) were purchased from Proteintech Group, Inc. (Chicago, IL, USA); and the primers for OPG, RANKL, $\mathrm{PGE}_{2}, \mathrm{COX}-2$ and $\mathrm{HO}-1$, and the small interfering RNAs (siRNAs) were purchased from GenePharma (Shanghai, China).

Cell culture. Human PDLCs were isolated with an explant culture technique from normal periodontal ligament tissues obtained from impacted wisdom teeth being removed or the teeth of patients undergoing orthodontic treatment. Informed consent was obtained from the patients prior to the surgery. The study was approved by the Ethics Committee of the School of Dentistry, Shandong University (Jinan, China). Briefly, the tissues were cut into $1-\mathrm{mm}^{2}$ explants and placed in $25-\mathrm{cm}^{2}$ culture bottles (Corning Inc., Corning, NY, USA) containing $100 \mathrm{U} / \mathrm{ml}$ penicillin $\mathrm{G}, 100 \mathrm{mg} / \mathrm{ml}$ streptomycin and $20 \%$ heat-inactivated FBS at $37^{\circ} \mathrm{C}$ in a humidified atmosphere of $5 \% \mathrm{CO}_{2}$ and $95 \%$ air. After 5-7 days, the cells were detached with $0.025 \%$ trypsin and $0.05 \%$ EDTA diluted with culture medium and then subcultured at a ratio of 1:2, and the concentration of the FBS was changed to $10 \%$; the other components in the medium remained the same. Cells between the 4th and 6th passages were used in the subsequent experiments.

Cell Counting kit-8 (CCK-8) assay. The toxicities of different concentrations of CORM-3 to the human PDLCs were assessed using a CCK-8 (WST-8) assay. The PDLCs were seeded and cultured in 96-well plates $(8,000$ cells/well). The cells were divided into five groups and were treated with CORM-3 at 0 , 100, 200, 400 and $800 \mu \mathrm{M}$ for $24 \mathrm{~h}$. After this, the CCK-8 reagent was added to every well, and the cells were incubated in a $37^{\circ} \mathrm{C}$ incubator for $\geq 0.5 \mathrm{~h}$ in the dark. The optical density (OD) values were read at $450 \mathrm{~nm}$ using a microplate reader (SPECTROstar Nano; BMG Labtech, Ortenberg, Germany). The data were collected every $0.5 \mathrm{~h}$ within $4 \mathrm{~h}$ of the addition of CCK- 8 .

RNA isolation and reverse transcription-quantitative polymerase chain reaction ( $R T-q P C R)$. PDLCs were grown in 6 -well plates (200,000 cells/well) and incubated in fresh medium containing various stimuli. For the first part of the experiment, the cells were divided into four groups as follows: Control group; LPS + nicotine group, in which the cells were incubated with LPS $(1 \mu \mathrm{g} / \mathrm{ml})$ and nicotine $(5 \mathrm{mM})$ for $24 \mathrm{~h}$; CORM-3 + LPS + nicotine group, in which the cells were pretreated with CORM-3 $(400 \mu \mathrm{M})$ for $6 \mathrm{~h}$ prior to incubation with LPS $(1 \mu \mathrm{g} / \mathrm{ml})$ and nicotine $(5 \mathrm{mM})$; and deactivated CORM-3 + LPS + nicotine group, in which the cells were pretreated with deactivated CORM-3 $(400 \mu \mathrm{M})$ for $6 \mathrm{~h}$ prior to incubation with LPS and nicotine. Deactivated CORM-3 was produced by dissolving CORM-3 in water to provide a $400 \mu \mathrm{M}$ aqueous solution, and putting the solution in a vacuum device for $24 \mathrm{~h}$ prior to use. 
For the second part of the experiment, the cells were divided into four groups as follows: Control group; scrambled siRNA control group, in which the cells were transiently transfected with scrambled siRNA; HO-1 siRNA + LPS + nicotine group, in which the cells were transiently transfected with HO-1 siRNA prior to incubation with LPS $(1 \mu \mathrm{g} / \mathrm{ml})$ and nicotine $(5 \mathrm{mM})$; and HO-1 siRNA + CORM-3 + LPS + nicotine group, in which the cells transiently transfected with HO-1 siRNA were pretreated with CORM-3 (400 $\mu \mathrm{M})$ for $6 \mathrm{~h}$ prior to incubation with LPS and nicotine.

Total RNA was extracted from the cells using TRIzol reagent (Invitrogen; Thermo Fisher Scientific, Inc., Waltham, MA, USA) according to the manufacturer's protocol. The RNA concentration was assessed using a UV spectrophotometer (GeneQuant pro DNA/RNA Calculator; GE Healthcare Life Sciences). The cDNA was amplified at $42^{\circ} \mathrm{C}$ by combining RNA, gDNA eraser, gDNA eraser buffer and RNase-free $\mathrm{dH}_{2} \mathrm{O}$, with PrimeScript RT enzyme mix, PrimeScript buffer, RT primer mix and RNase free $\mathrm{dH}_{2} \mathrm{O}$, using RNA PCR kit (AMV) Ver.3.0 (Takara Bio, Inc., Otsu, Japan) according to the manufacturer's protocol. qPCR was performed using SYBR Premix Ex Taq (Takara Bio., Inc.) with a Biometra thermocycler (TGradient; Biometra GmbH, Göttingen, Germany). The reaction conditions for the qPCR were 45 cycles of denaturation at $95.8^{\circ} \mathrm{C}$ for $30 \mathrm{sec}$, annealing at $55-60.8^{\circ} \mathrm{C}$ for $30 \mathrm{sec}$, and extension at $72.8^{\circ} \mathrm{C}$ for $1 \mathrm{~min}$. The primer sequences for differentiation markers were as follows: $\mathrm{PGE}_{2}$ forward, 5'-CGATGCTCATGC TCTTCGC-3' and reverse, 5'-GGGAGACTGCATAGATGAC AGG-3'; COX-2 forward, 5'-CTGGCGCTCAGCCATACAG-3' and reverse, 5'-CGCACTTATACTGGTCAAATCCC-3'; RANKL forward, 5'-TCCATGTTCGTGGCCCTC-3' and reverse, 5'-GCAGTGAGTGCCATCTTCTG-3'; OPG forward, 5'-GTGTGCGAATGCAAGGAAGG-3' and reverse, 5'-CCACT CCAAATCCAGGAGGG-3'; HO-1 forward, 5'-AGGCCAAGA CTGCGTTCCT-3' and reverse, 5'-AACTGTCGCCACCAGAA AGCTGAG-3'; GAPDH forward, 5'-GCACCGTCAAGGCT GAGAAC-3' and reverse, 5'-TGGTGAAGACGCCAGTGGA-3'. The $2^{-\Delta \Delta C q}$ method was used for quantification (27).

Western blot analysis. PDLCs were grown in 6-well plates and incubated in fresh medium containing various stimuli; the groups were established as described above for the first and second part of the experiment. The cells in the 6-well plates from each set of experiments were harvested and washed three times in cold phosphate-buffered saline. The cells were then solubilized in ice-cold radioimmunoprecipitation assay lysis buffer (Solarbio, Beijing, China), and after $30 \mathrm{~min}$ on ice, the lysates were clarified by centrifugation with the speed of $12,000 \mathrm{x}$ g at $4^{\circ} \mathrm{C}$ for $5 \mathrm{~min}$. The protein samples $(20 \mu \mathrm{g})$, which were quantified using a BCA kit (Solarbio), were mixed with a quarter-volume of 5X SDS-PAGE loading buffer, boiled for $5 \mathrm{~min}$ to denature, and then separated by $10 \%$ SDS-polyacrylamide electrophoresis (Gel Preparation kit; Boster Biological Technology, Pleasanton, CA, USA). Following electrophoresis, the proteins were transferred to polyvinylidene fluoride membranes $(0.45 \mu \mathrm{m})$ via electrophoretic transfer. The membranes were blocked in 5\% dry milk $(1 \mathrm{~h})$, rinsed and incubated with antibodies (COX-2, 1:1,000; OPG, $1 \mu \mathrm{g} / \mathrm{ml}$; RANKL, $1 \mu \mathrm{g} / \mathrm{ml}$; PGE $_{2}, 1: 1,000$; HO- 1 , $4 \mu \mathrm{g} / \mathrm{ml}$; GAPDH, 1:2,000; $\alpha$-tubulin, 1:2,000) in Tris-buffered

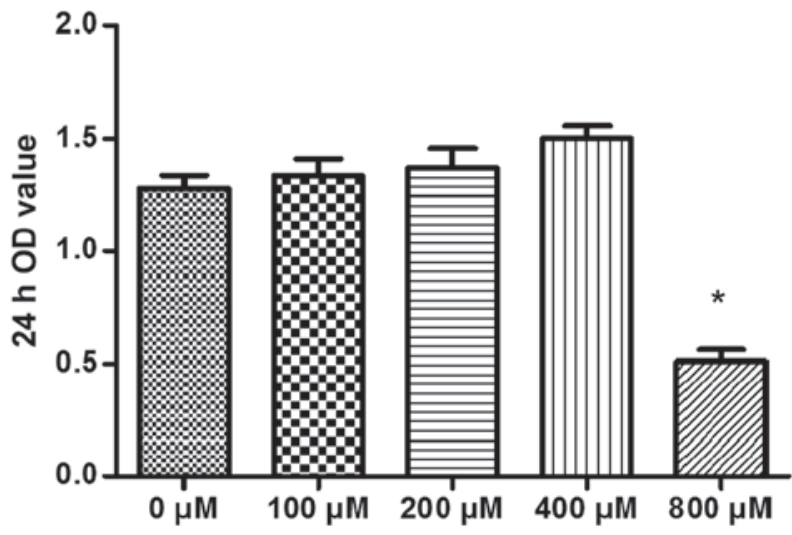

Figure 1. Toxicities of different concentrations of CORM-3 to human periodontal ligament cells. Cells were treated with CORM-3 at 0, 100, 200, 400 and $800 \mu \mathrm{M}$ for $24 \mathrm{~h}$ in 96 -well plates (8,000 cells/well). Cell viability was determined using a Cell Counting kit- 8 assay. Data are expressed as the mean OD value + standard deviation. Results of a representative experiment are depicted, and a total number of three experiments was performed. ${ }^{*} \mathrm{P}<0.05$ vs. the $0 \mu \mathrm{M}$ group. CORM, carbon monoxide-releasing molecule; OD, optical density.

saline (TBS) overnight at $4^{\circ} \mathrm{C}$. The primary antibodies were then removed by washing the membranes three times in TBS. The primary antibodies were labelled via incubation with $0.1 \mathrm{mg} / \mathrm{ml}$ HRP-labeled secondary antibodies for $1 \mathrm{~h}$. Following three washes in TBS, the bands were visualised using a western blot chemiluminescence reagent (EMD Millipore, Billerica, MA, USA) and ChampChem ${ }^{\mathrm{TM}}$ automated chemiluminescence system (Sage Creation Science Co., Ltd., Beijing, China), and then imaged using Lane 1D 4.0 gel imaging analysis software (Sage Creation Science Co., Ltd.).

Transient transfection. Human PDLCs were transfected with HO-1 siRNA as follows. The siRNA target sequences for HO-1 were: forward, 5'-GGGUCCUUACAUUCAGCUUTT-3' and reverse, 5'-AAGCUGAGUGUAAGGACCCTT-3'. Four groups were established as defined above for the second part of the experiment. In brief, the cells in 6-well plates $(150,000$ cells/well) were transfected with $5 \mu 1$ siRNA for $6 \mathrm{~h}$ using Lipofectamine ${ }^{\circledR} 3000$ Transfection reagent (Invitrogen; Thermo Fisher Scientific, Inc.) according to the manufacturer's protocol. The cells were cultured in Opti-MEM ${ }^{\circledR}$ Reduced Serum Medium (Gibco; Thermo Fisher Scientific, Inc.) and transiently transfected with the scrambled siRNA or HO-1 siRNA, followed by treatment with LPS and nicotine in the presence or absence of CORM-3.

Statistical analysis. Differences among the groups were analyzed using one-way analysis of variance, and comparisons between groups were performed using Tukey's test. All values are expressed as the mean and standard deviation, and $\mathrm{P}<0.05$ was considered to indicate a statistically significant difference. The statistical analysis was conducted using SPSS version 22.0 software (IBM Corp., Armonk, NY, USA).

\section{Results}

Cytotoxicity of CORM-3 to human periodontal ligament cells. To evaluate the cytotoxicity of CORM-3 to human PDLCs, the 
A

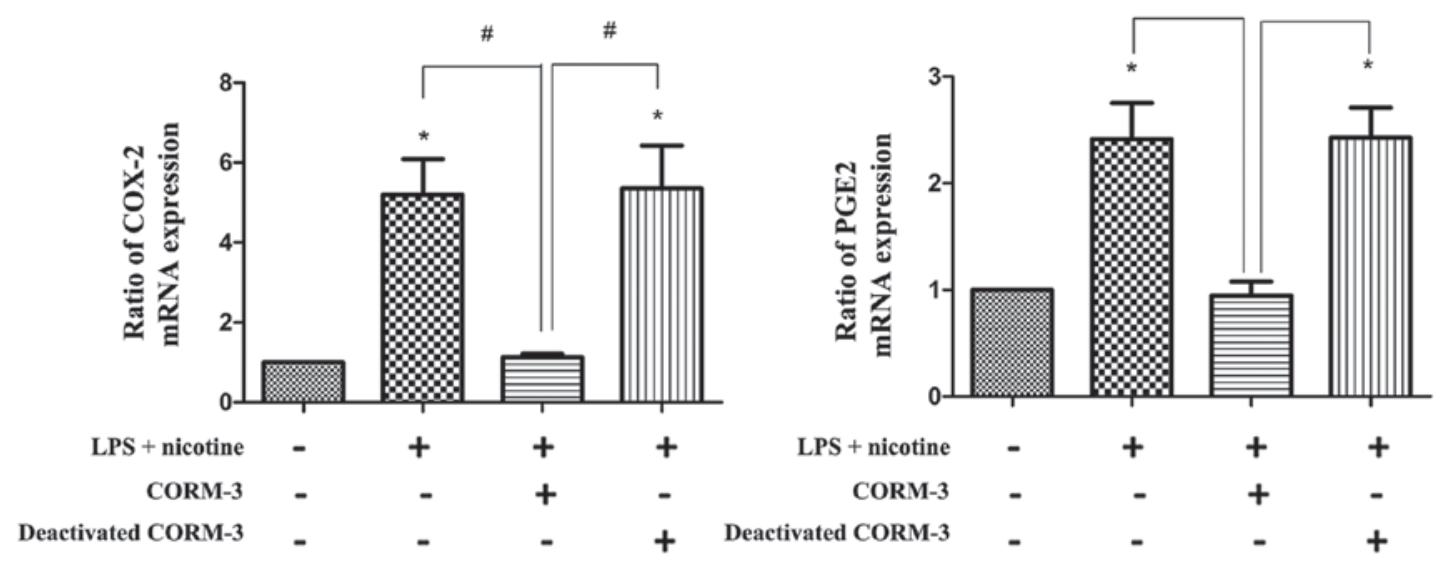

B
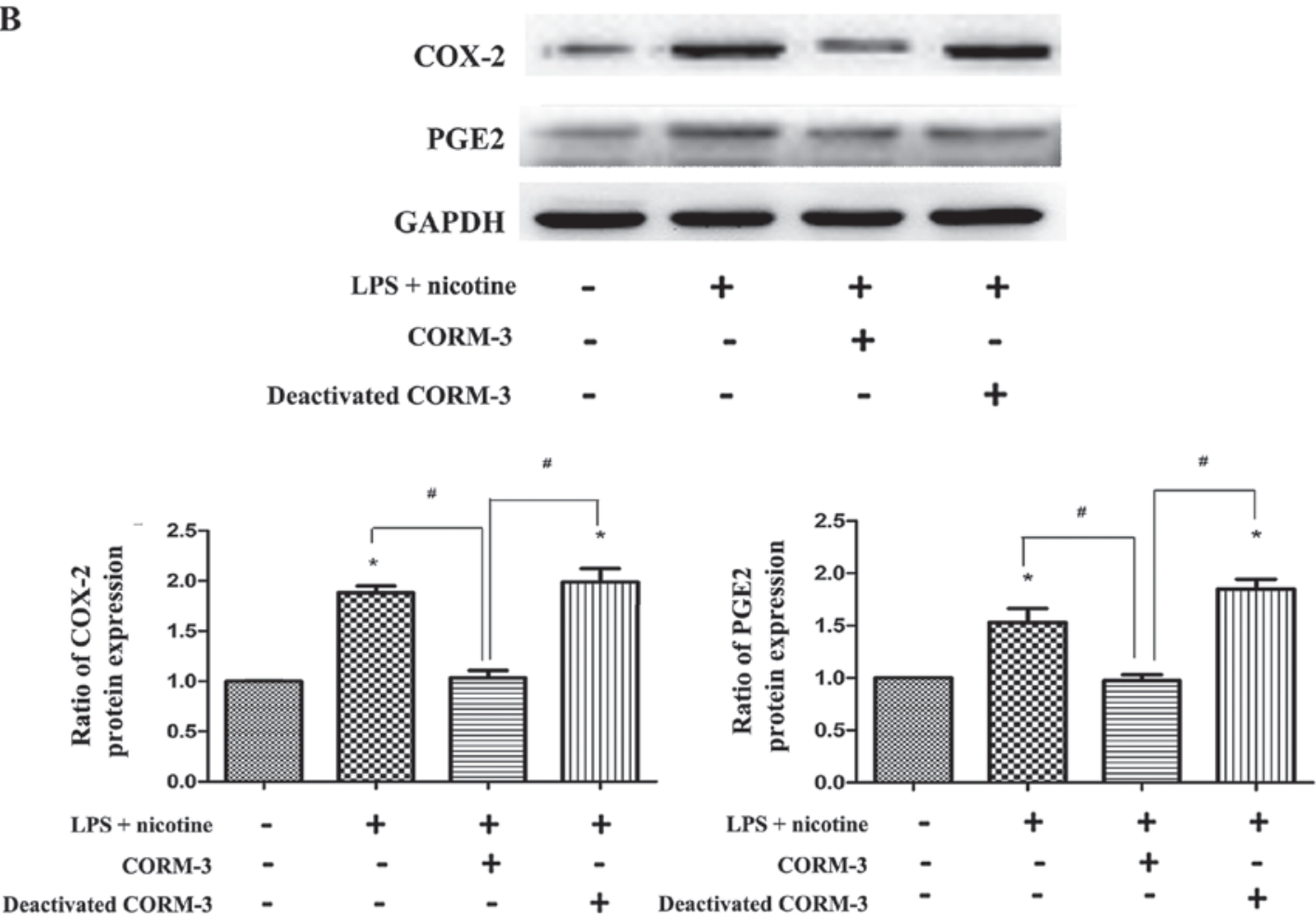

Figure 2. Effects of CORM-3 on the mRNA and protein expression of COX-2 and $\mathrm{PGE}_{2}$ in human PDLCs stimulated with LPS and nicotine. (A) Effects of CORM-3 on COX-2 andPGE 2 mRNA expression in HPDLCs. Cells were divided into four groups: Control; LPS + nicotine, in which cells were incubated with LPS $(1 \mu \mathrm{g} / \mathrm{ml})$ and nicotine $(5 \mathrm{mM})$ for $24 \mathrm{~h}$; CORM-3 + LPS + nicotine, in which cells were treated with CORM-3 (400 $\mu \mathrm{M})$ for $6 \mathrm{~h}$ prior to LPS and nicotine; and deactivated CORM-3 + LPS + nicotine, in which cells were treated with deactivated CORM-3 (400 $\mu \mathrm{M})$ prior to LPS and nicotine. COX-2 and $\mathrm{PGE}_{2}$ mRNA expression levels were determined by reverse transcription-quantitative polymerase chain reaction. (B) Protein expression levels of COX-2 and $\mathrm{PGE}_{2}$ were determined by western blotting. GAPDH was used to demonstrate equal sample loading. Results of a single experiment are depicted and are representative of the three different experiments that were performed. ${ }^{*} \mathrm{P}<0.05$ vs. the control group; ${ }^{~} \mathrm{P}<0.05$ as indicated. CORM, carbon monoxide-releasing molecule; COX, cyclooxygenase; $\mathrm{PGE}_{2}$, prostaglandin $\mathrm{E}_{2}$; PDLCs, periodontal ligament cells; LPS, lipopolysaccharide.

PDLCs were treated with CORM-3 at concentrations of 0,100 , 200,400 and $800 \mu \mathrm{M}$ for $24 \mathrm{~h}$ in 96 -well plates (8,000 cells/well). After $24 \mathrm{~h}$, the OD values were determined (Fig. 1). CORM-3 at $800 \mu \mathrm{M}$ was significantly cytotoxic to human PDLCs, but $400 \mu \mathrm{M}$ of CORM-3 exhibited no significant cytotoxicity to the cells. The cells treated with CORM-3 at $400 \mu \mathrm{M}$ exhibited a certain degree of cell proliferation, but this finding was not statistically significant (Fig. 1). Similar results were obtained in three independent experiments. Therefore, a CORM-3 concentration of $400 \mu \mathrm{M}$ was selected for use in subsequent experiments.
CORM-3 suppresses the nicotine- and LPS-induced inflammatory response via the release of $C O$. To determine the effects of CORM-3 on the inflammatory response and osteoclastogenesis in vitro, the expression of $\mathrm{COX}-2, \mathrm{PGE}_{2}, \mathrm{OPG}$ and RANKL induced in human PDLCs by LPS $(1 \mu \mathrm{g} / \mathrm{ml})$ and nicotine $(5 \mathrm{mM})$ with or without CORM-3 $(400 \mu \mathrm{M})$ pretreatment was examined. Co-treatment with LPS and nicotine resulted in increased COX-2, PGE 2 (Fig. 2) and RANKL (Fig. 3) expression. However, with CORM-3 pretreatment, an inhibitory effect on these three inflammatory cytokines was observed, and the 
A

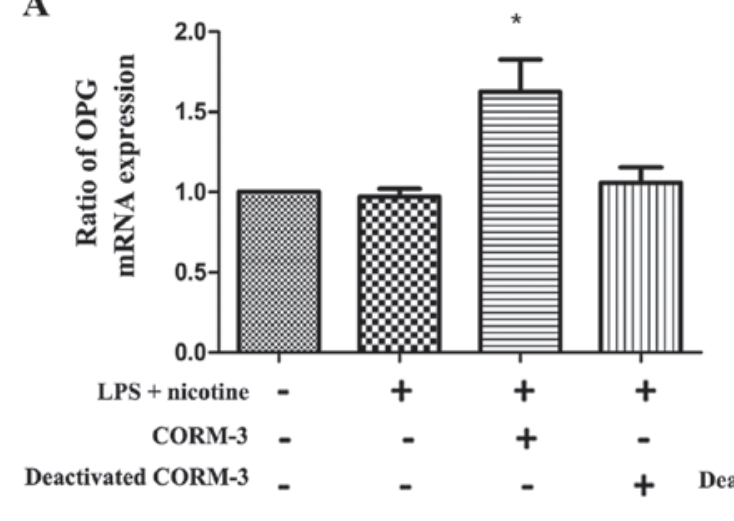

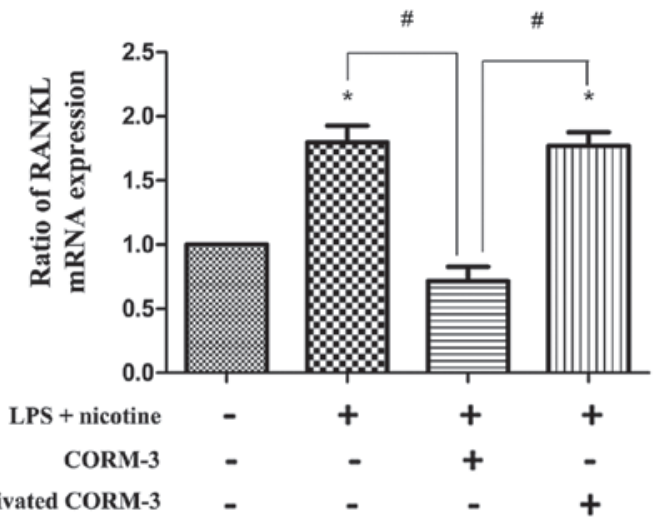

B
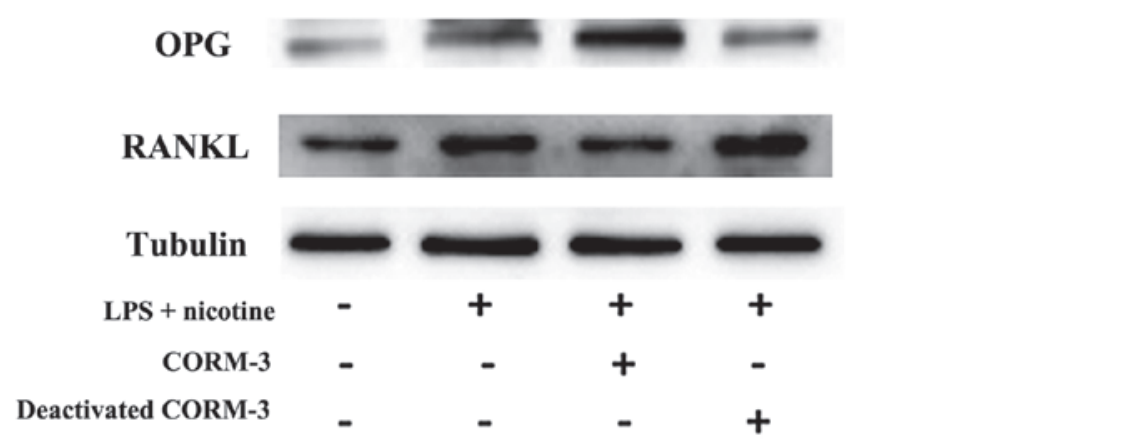

Deactivated CORM-3 $\quad-\quad \quad-\quad-\quad+\quad+$

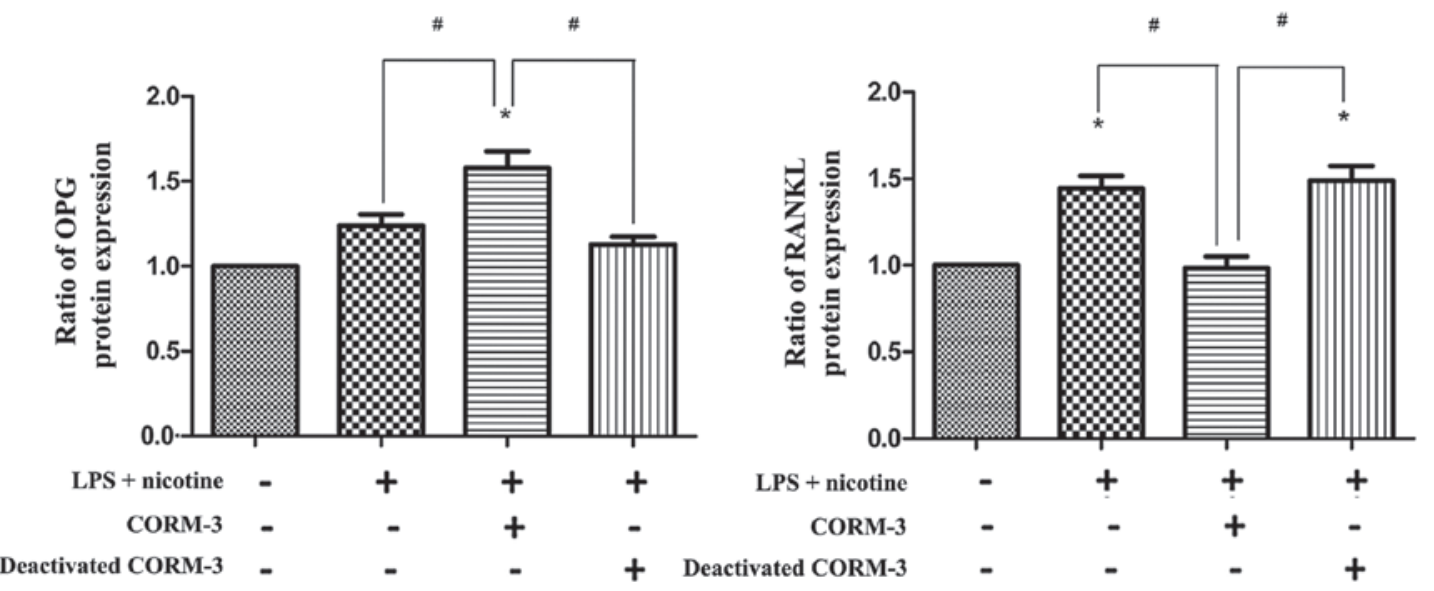

Figure 3. Effects of CORM-3 on the mRNA and protein expression of OPG and RANKL in human PDLCs stimulated with LPS and nicotine. (A) Effects of CORM-3 on OPG and RANKL mRNA expression in HPDLCs. Cells were divided into four groups: Control; LPS + nicotine, in which cells were incubated with LPS $(1 \mu \mathrm{g} / \mathrm{ml})$ and nicotine $(5 \mathrm{mM})$ for $24 \mathrm{~h}$; CORM-3 + LPS + nicotine, in which cells were treated with CORM-3 (400 $\mu \mathrm{M})$ for $6 \mathrm{~h}$ prior to LPS and nicotine; and deactivated CORM-3 + LPS + nicotine, in which cells were treated with deactivated CORM-3 (400 $\mu$ M) prior to LPS and nicotine. OPG and RANKL mRNA expression levels were determined by reverse transcription-quantitative polymerase chain reaction. (B) Protein expression levels of OPG and RANKL were determined by western blotting. Tubulin was used to demonstrate equal sample loading. Results of a representative experiment are depicted. A total of three experiments was performed. ${ }^{*} \mathrm{P}<0.05$ vs. the control group; ${ }^{~} \mathrm{P}<0.05$ as indicated. CORM, carbon monoxide-releasing molecule; OPG, osteoprotegerin; RANKL, receptor activator of nuclear factor-кB ligand; PDLCs, periodontal ligament cells; LPS, lipopolysaccharide.

expression of OPG exhibited a significant increase (Fig. 3). By contrast, deactivated CORM-3, which is not able to release $\mathrm{CO}$, did not attenuate LPS- and nicotine-induced inflammatory cytokine expression in the human PDLCs, which demonstrated that the effect of CORM-3 is mediated by $\mathrm{CO}$. These results were verified by the evaluation of mRNA (Figs. 2A and 3A) and protein (Figs. 2B and 3B) expression. The expression levels of COX-2, $\mathrm{PGE}_{2}$ and RANKL in the CORM-3 + LPS + nicotine group were decreased compared with those in the LPS + nicotine group and the deactivated CORM-3 + LPS + nicotine group. The expression levels of OPG were increased in the CORM-3 + LPS + nicotine group in comparison with those in the LPS + nicotine group and deactivated CORM-3 + LPS + nicotine group.

CORM-3 promotes HO-1 expression in HPDLCs incubated with or without LPS and nicotine via the release of $C O$. First, human PDLCs were examined for HO-1 expression induced by CORM-3 and it was found that HO-1 expression was upregulated significantly compared with that in the control group, as shown in Fig. 4. In addition, deactivated CORM-3 did not exhibit an inductive effect on HO-1 expression, which indicated that the effect of CORM-3 was mediated by CO. These results were confirmed for HO-1 mRNA (Fig. 4A) and 

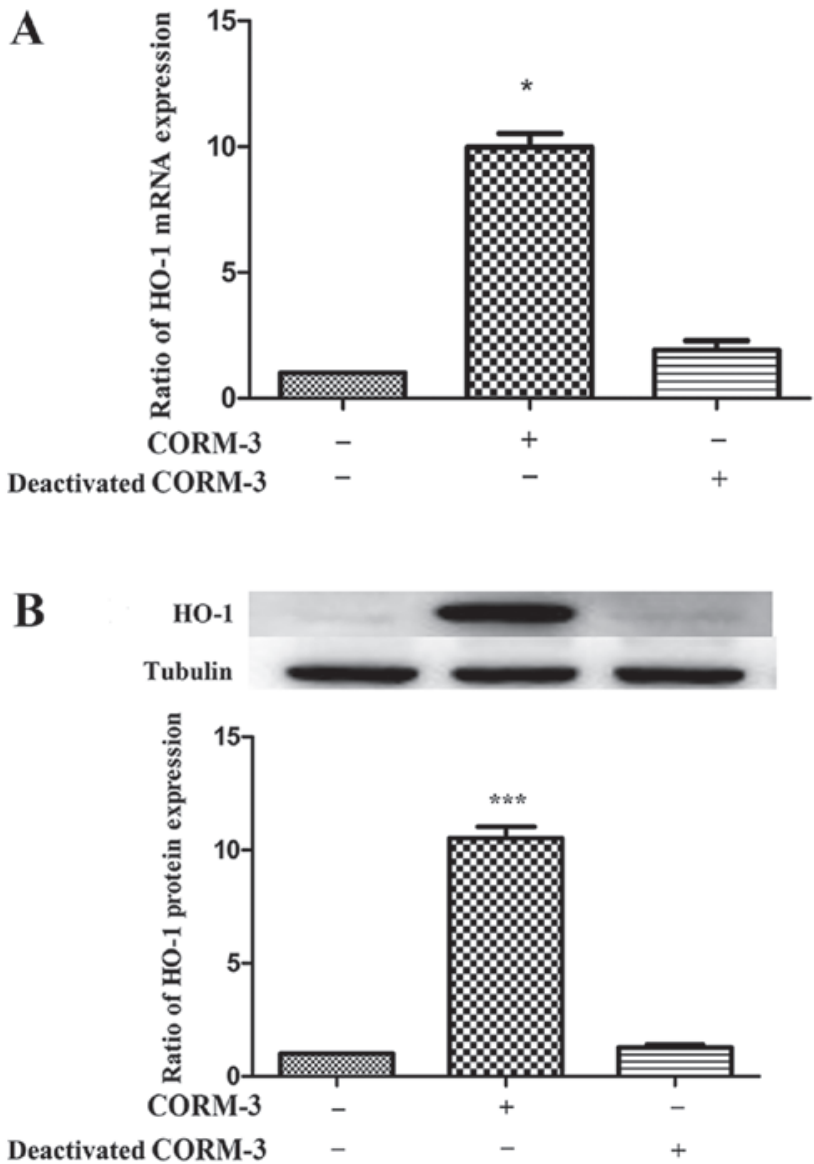

Figure 4. Effects of CORM-3 on HO-1 mRNA and protein expression in human periodontal ligament cells. (A) Cells were divided into three groups: Control; CORM-3, in which cells were treated with CORM-3 $(400 \mu \mathrm{M})$ for $6 \mathrm{~h}$; and deactivated CORM-3, in which cells were treated with deactivated CORM-3 $(400 \mu \mathrm{M})$ for $6 \mathrm{~h}$. HO-1 mRNA expression was determined by reverse transcription-quantitative polymerase chain reaction. (B) Protein expression levels of HO-1 were determined by western blotting. Tubulin was used to demonstrate equal sample loading. Results of a representative experiment are depicted. A total of three experiments was performed. $\mathrm{P}<0.05$ and ${ }^{* * *} \mathrm{P}<0.01$ vs. the control group. CORM, carbon monoxide-releasing molecule; HO-1, heme oxygenase-1.

protein expression (Fig. 4B). Following this, human PDLCs were examined for HO-1 expression induced by LPS and nicotine, with or without CORM-3 pretreatment. As shown in Fig. 5, nicotine- and LPS-induced HO-1 expression levels were comparable to those in the control cultures. Furthermore, CORM-3 pretreatment significantly promoted the mRNA and protein expression of HO-1 in human PDLCs compared with the respective levels in the nicotine + LPS group (Fig. 5). It may be concluded that CORM-3 promotes HO-1 expression and, notably, its expression was elevated compared with that in human PDLCs only co-treated with LPS and nicotine. It was also observed that deactivated CORM-3, which is not able to release $\mathrm{CO}$, did not have an inductive effect on HO-1.

Effect of silencing HO-1 on the LPS- and nicotine-induced inflammatory response with or without CORM-3 pretreatment. To examine whether HO-1 expression is involved in the nicotine- and LPS-mediated induction of COX-2, $\mathrm{PGE}_{2}$, OPG and RANKL production, human PDLCs were transfected with HO-1 siRNA and then subjected to $24 \mathrm{~h}$ exposure
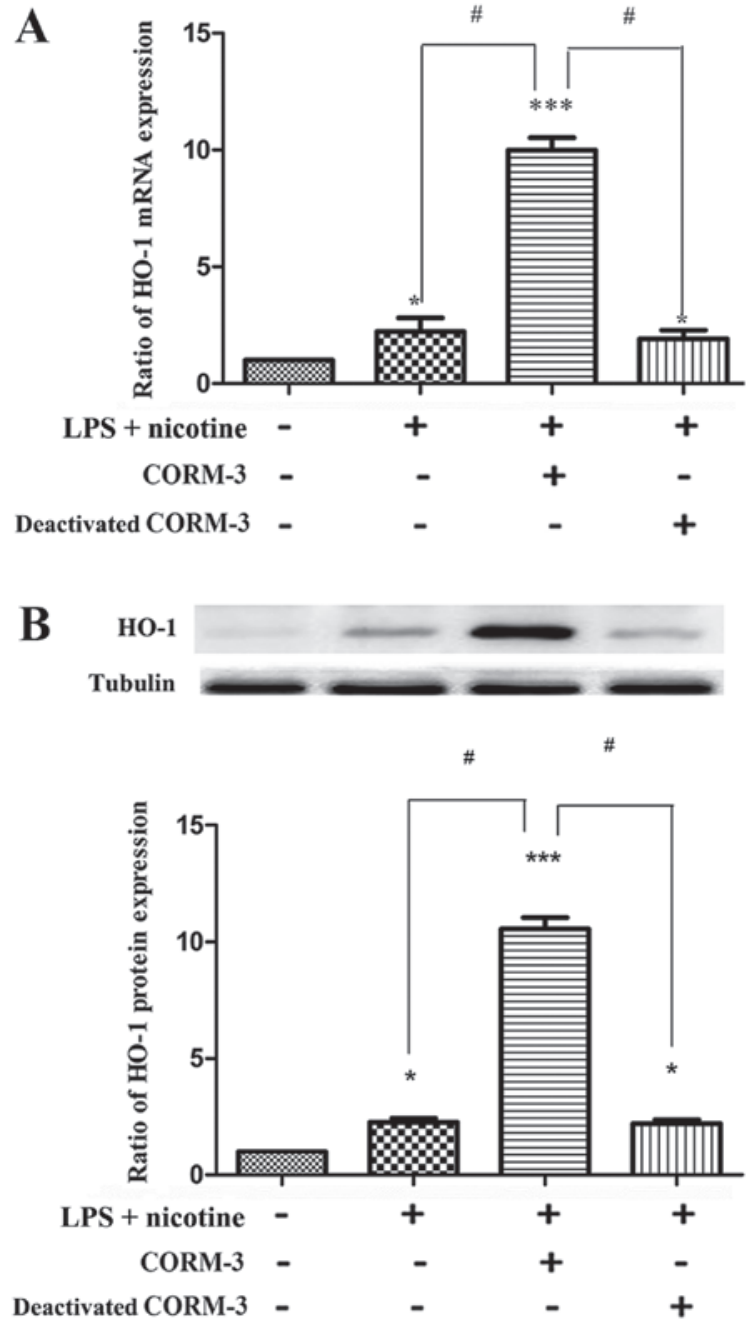

Figure 5. Effects of CORM-3 on HO-1 mRNA and protein expression in human periodontal ligament cells incubated with LPS and nicotine. (A) Cells were divided into four groups: Control; LPS + nicotine, in which cells were incubated with LPS $(1 \mu \mathrm{g} / \mathrm{ml})$ and nicotine $(5 \mathrm{mM})$ for $24 \mathrm{~h}$; CORM-3 + LPS + nicotine, in which cells were treated with CORM-3 $(400 \mu \mathrm{M})$ for $6 \mathrm{~h}$ prior to LPS and nicotine; and deactivated CORM-3 + LPS + nicotine, in which the cells were treated with deactivated CORM-3 $(400 \mu \mathrm{M})$ prior to LPS and nicotine. HO-1 mRNA expression levels were determined by reverse transcription-quantitative polymerase chain reaction. (B) Protein expression levels of HO-1 were determined by western blotting. Tubulin was used to demonstrate equal sample loading. Results of a representative experiment are depicted. A total of three experiments was performed. ${ }^{*} \mathrm{P}<0.05$ and ${ }^{* * *} \mathrm{P}<0.01$ vs. the control group; ${ }^{\#} \mathrm{P}<0.05$ as indicated. CORM, carbon monoxide-releasing molecule; HO-1, heme oxygenase-1; LPS, lipopolysaccharide.

to LPS and nicotine with or without CORM-3 pretreatment for $6 \mathrm{~h}$. The mRNA and protein expression levels of HO-1 following transfection with HO-1 siRNA were significantly suppressed (Fig. 6). As shown in Figs. 7 and 8, HO-1 siRNA transfection abolished the anti-inflammatory effects of CORM-3, and the COX-2, $\mathrm{PGE}_{2}$ and RANKL expression levels were not downregulated by CORM-3. These results were verified by mRNA (Figs. 7A and 8A) and protein (Figs. 7B and 8B) expression profiles. The expression levels of $\mathrm{COX}-2, \mathrm{PGE}_{2}$ and RANKL in the HO-1 siRNA + CORM-3 + LPS + nicotine group were increased in comparison with those in the control groups, and were not statistically different in comparison with those in the HO-1 siRNA + LPS + nicotine group. Following transient transfection with HO-1 siRNA, 

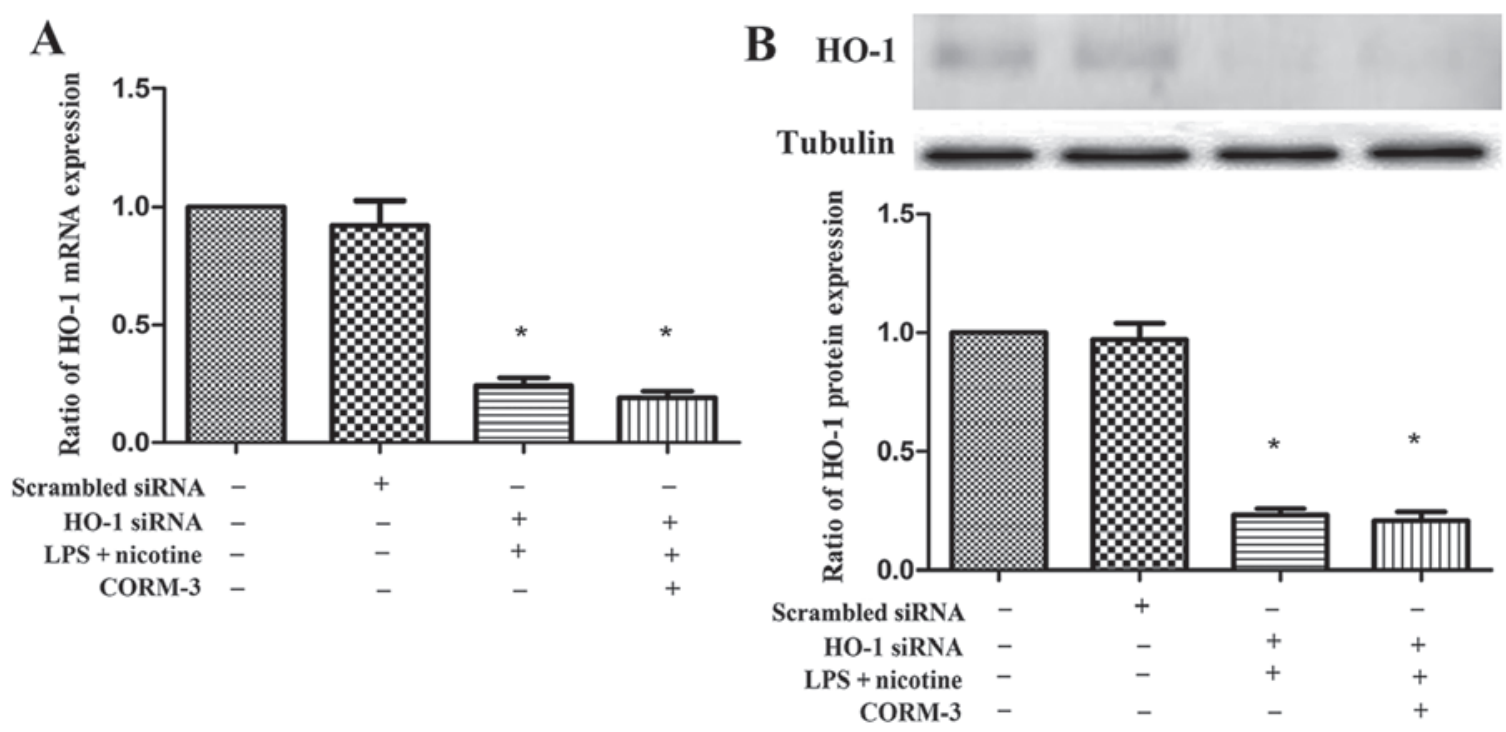

Figure 6. HO-1 expression in human periodontal ligament cells transfected with HO-1 siRNA. (A) Cells were divided into four groups: Control; scrambled siRNA control, in which cells were transiently transfected with scrambled siRNA; HO-1 siRNA + LPS + nicotine, in which cells were transiently transfected with HO-1 siRNA prior to incubation with LPS $(1 \mu \mathrm{g} / \mathrm{ml})$ and nicotine $(5 \mathrm{mM})$; and HO-1 siRNA + CORM-3 + LPS + nicotine, in which cells transiently transfected with HO-1 siRNA were treated with CORM-3 $(400 \mu \mathrm{M})$ for $6 \mathrm{~h}$ prior to LPS and nicotine. HO-1 mRNA expression levels were determined by reverse transcription-quantitative polymerase chain reaction. (B) Protein expression levels of HO-1 were determined by western blotting. Tubulin was used to demonstrate equal sample loading. Results of a representative experiment are depicted. A total of three experiments was performed. "P<0.05 vs. the control group. HO-1, heme oxygenase-1; siRNA, small interfering RNA; LPS, lipopolysaccharide; CORM, carbon monoxide-releasing molecule.

CORM-3 exhibited no effect on OPG expression (Fig. 8). However, it was observed that the ratio of OPG/RANKL in the HO-1 siRNA + CORM-3 + LPS + nicotine group was decreased in comparison with that in the control groups and was not statistically different in comparison with that in HO-1 siRNA + LPS + nicotine group (Fig. 8C).

\section{Discussion}

Previous studies have reported on the nicotine- and LPS-mediated induction of proinflammatory cytokines, including COX-2, $\mathrm{PGE}_{2}$ and RANKL, in human PDLCs (28-32). In addition, CORM-3 has been demonstrated to modulate inflammatory processes in a variety of in vivo and in vitro models $(33,34)$. However, to the best of our knowledge, the inhibitory effect of CORM-3 on the induction of proinflammatory cytokines by LPS and nicotine in human PDLCs has not been demonstrated. In the present study, the effect of CORM-3 on the LPS and nicotine-stimulated inflammatory response and the role of HO-1 in the process was investigated.

Human PDLCs were selected for use in the study as they are the group of cells that are most highly affected by LPS and nicotine in periodontitis; they also play the most important role in the regeneration of periodontal attachment (3). The host inflammatory response to smoking and dental plaque are considered major causative factors in the local tissue destruction observed in periodontitis $(13,14,19)$; thus, the present study was conducted using nicotine- and LPS-treated human PDLCs with pretreatment with or without CORM-3.

The results of the study suggested that when human PDLCs were exposed to LPS and nicotine, COX-2 and $\mathrm{PGE}_{2}$ production increased. The results also demonstrated that LPS and nicotine upregulated RANKL expression and downregulated OPG expression in human PDLCs. Furthermore, it was found that pretreatment with CORM-3 effectively reduced LPS- and nicotine-induced COX-2, PGE $_{2}$ and RANKL levels and promoted OPG levels in human PDLCs. By contrast, deactivated CORM-3, which is not able to release CO, did not attenuate LPS- and nicotine-induced inflammatory cytokine expression in human PDLCs. Thus, it may be hypothesized that CORM-3exertsanti-inflammatory and anti-osteoclastogenic effects via the release of $\mathrm{CO}$.

Among the many molecules involved in the inflammatory process, COX-2 is highly expressed during periodontal disease and is responsible for the production of $\mathrm{PGE}_{2}$, which is involved in inflammation $(35,36)$. Studies have reported that $\mathrm{PGE}_{2}$ mediates bone resorption through the activation of osteoclasts and RANKL in vitro (10) and in vivo (37). RANKL is essential in osteoclastogenesis, and $\mathrm{PGE}_{2}$ is considered a major target for periodontal therapy since it is inducible and present in the cells involved in periodontal disease $(37,38)$. These inflammatory molecules activate osteoclasts and induce bone resorption as a result of an exacerbated host response (39).

Previous studies have reported that HO-1 induction by proinflammatory cytokines, nitric oxide, mechanical stress and hydrogen peroxide may exert cytoprotective and antiinflammatory effects in human pulp and PDLCs via the production of $\mathrm{CO}$ with heme as its substrate (40-43). In addition, HO-1 serves critical roles in the regulation of cell growth and differentiation and in the control of cellular responses to cytokines and other stresses (44). The results of the present study demonstrated that LPS and nicotine induced HO-1 expression in human PDLCs, and CORM-3 induced HO-1 expression more strongly than the combination of LPS and nicotine.

The present authors hypothesized that HO-1 induction by CORM-3 in human PDLCs may be responsible for the antiinflammatory effects of CORM-3 against the inflammation 
A
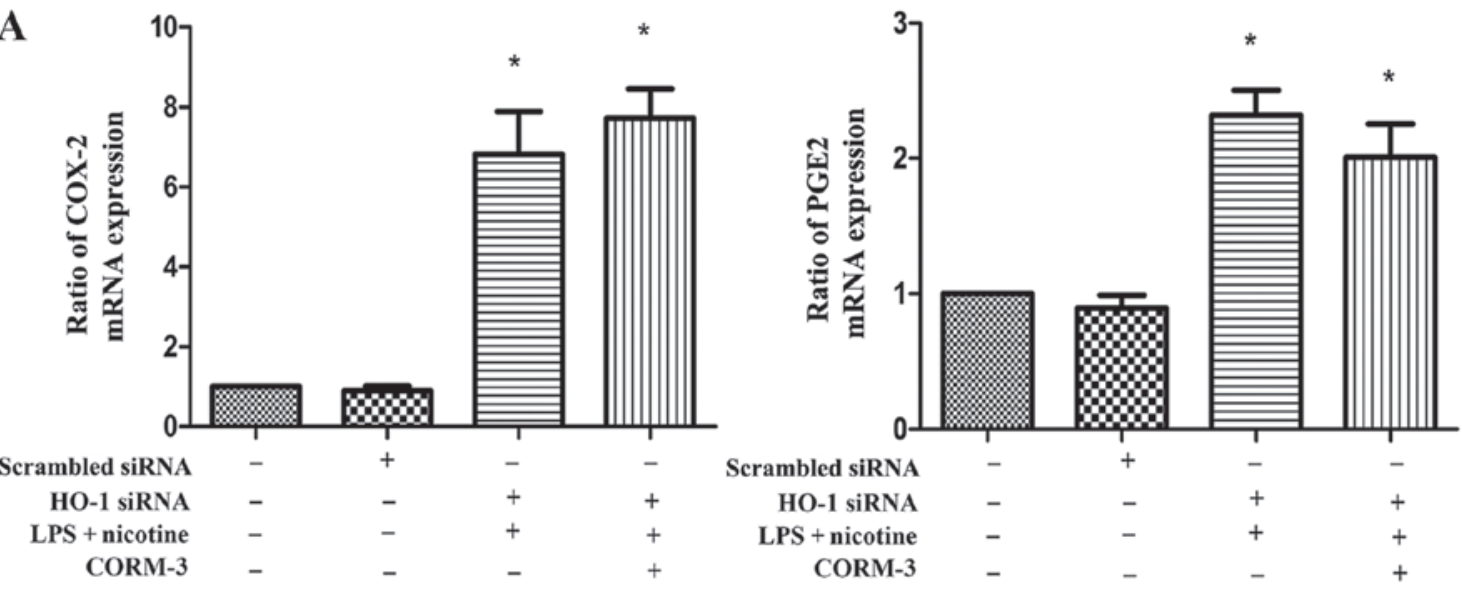

B
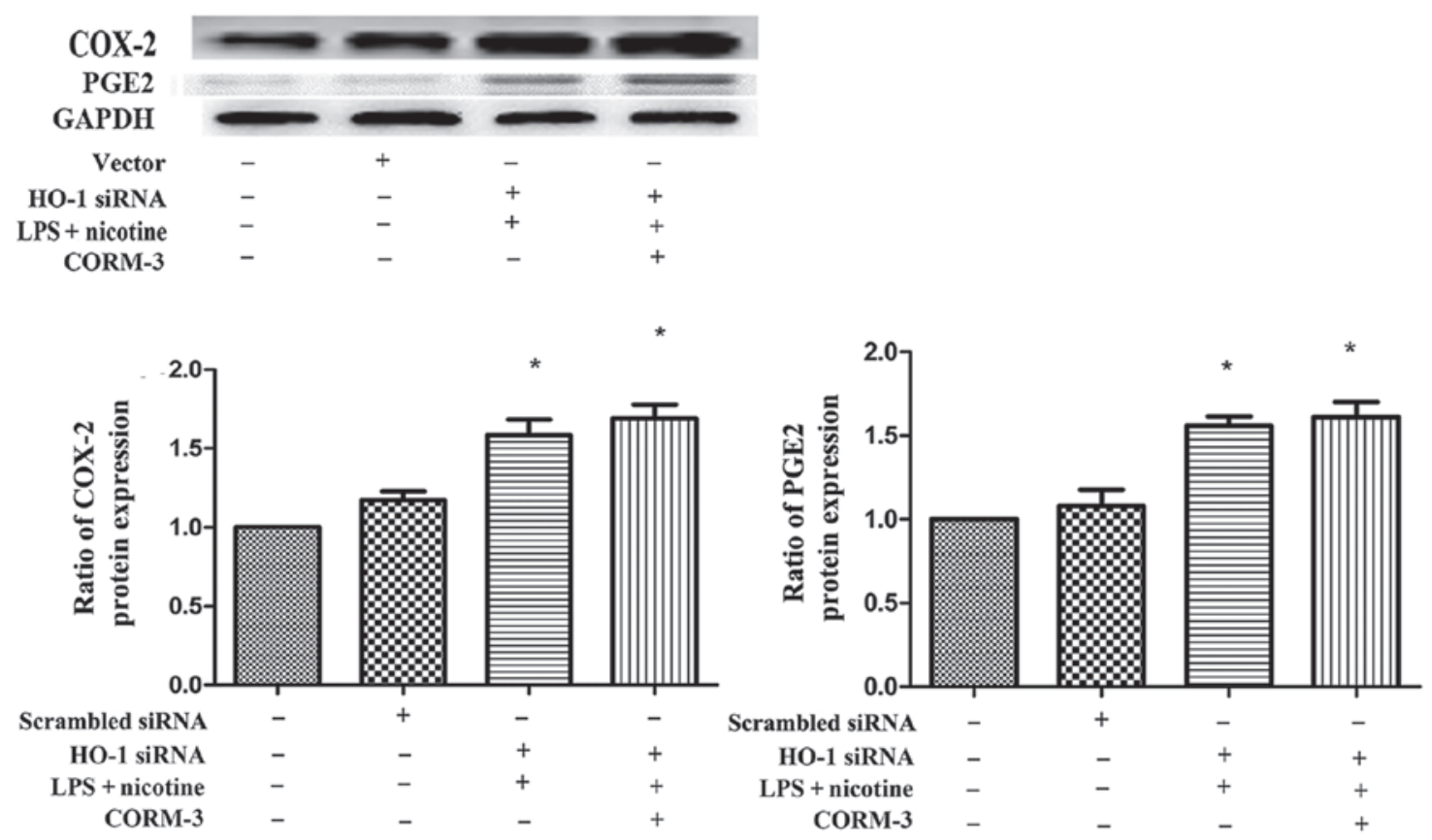

Figure 7. COX-2 and $\mathrm{PGE}_{2}$ expression in human periodontal ligament cells following HO-1 siRNA transfection. (A) Cells were divided into four groups: Control; scrambled siRNA control, in which cells were transiently transfected with scrambled siRNA; HO-1 siRNA + LPS + nicotine, in which the cells were transiently transfected with HO-1 siRNA prior to incubation with LPS $(1 \mu \mathrm{g} / \mathrm{ml})$ and nicotine $(5 \mathrm{mM})$; and HO-1 siRNA + CORM-3 + LPS + nicotine, in which cells transiently transfected with HO-1 siRNA were treated with CORM-3 $(400 \mu \mathrm{M})$ for $6 \mathrm{~h}$ prior to LPS and nicotine. COX-2 and PGE 2 mRNA expression levels were determined by reverse transcription-quantitative polymerase chain reaction. (B) Protein expression levels were determined by western blotting. GAPDH was used to demonstrate equal sample loading. Results of a representative experiment are depicted. A total of three experiments was performed. "P<0.05 vs. the control group. COX, cyclooxygenase; $\mathrm{PGE}_{2}$, prostaglandin $\mathrm{E}_{2}$; HO-1, heme oxygenase-1; siRNA, small interfering RNA; CORM, carbon monoxide-releasing molecule; LPS, lipopolysaccharide.

induced by LPS and nicotine. One finding of the present study was that CORM-3 inhibited the inflammatory effects induced by the combination of LPS and nicotine. The inhibitory effect of CORM-3 may have been mediated via the release of $\mathrm{CO}$, since the deactivated CORM-3 did not suppress the inflammatory response to LPS and nicotine stimulation. In addition, following HO-1 siRNA transfection, the anti-inflammatory effects of CORM-3 as a downregulator of COX-2 and $\mathrm{PGE}_{2}$ expression and RANKL production vanished and the ratio of OPG/RANKL decreased concurrently. These findings indicate that the anti-inflammatory effects of CORM-3 are dependent upon HO-1 overexpression in human PDLCs. Based on these findings, it is proposed that CORM-3, as a controllable extrinsic molecule, represents a novel preventive or therapeutic agent for periodontitis. A number of studies have postulated putative mechanisms by which HO-1 exerts its anti-inflammatory effect $(17,18)$; however, these mechanisms require further elucidation. In the future, the present research group plans to study these cell-signalling pathways and mechanisms further.

In conclusion, the results of the present study demonstrate for the first time that anti-inflammatory and anti-osteoclastogenic effects of CORM-3 proceed via HO-1-dependent pathways in periodontal disease models, which are mediated through the expression of OPG/RANKL and COX-2/PGE 2 . Thus, it is suggested that CORM-3 may be of potentially useful 
A
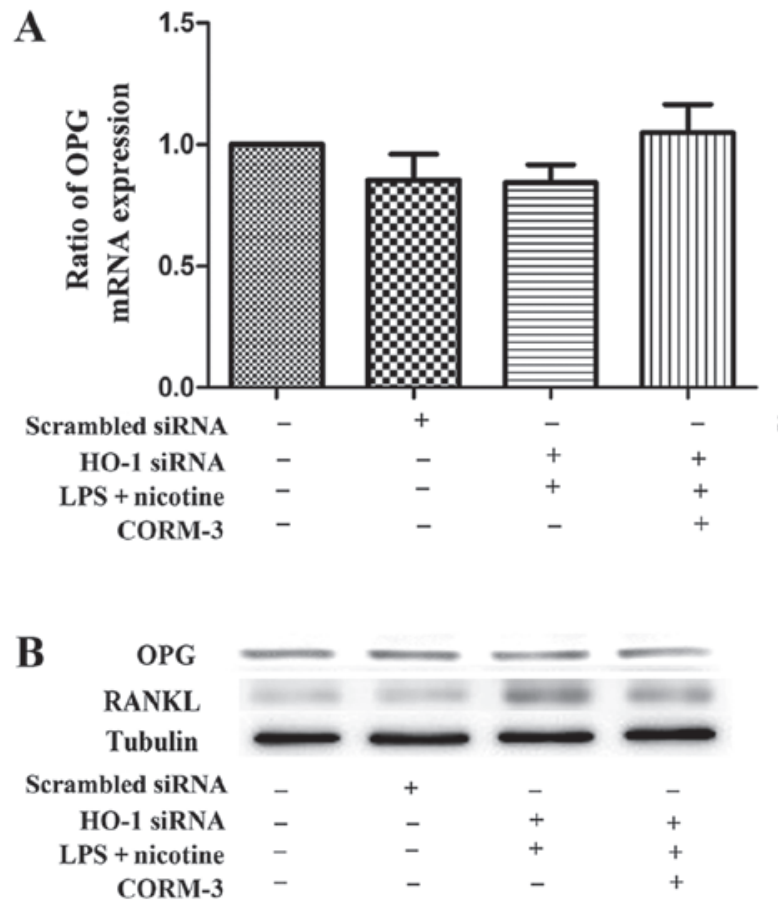
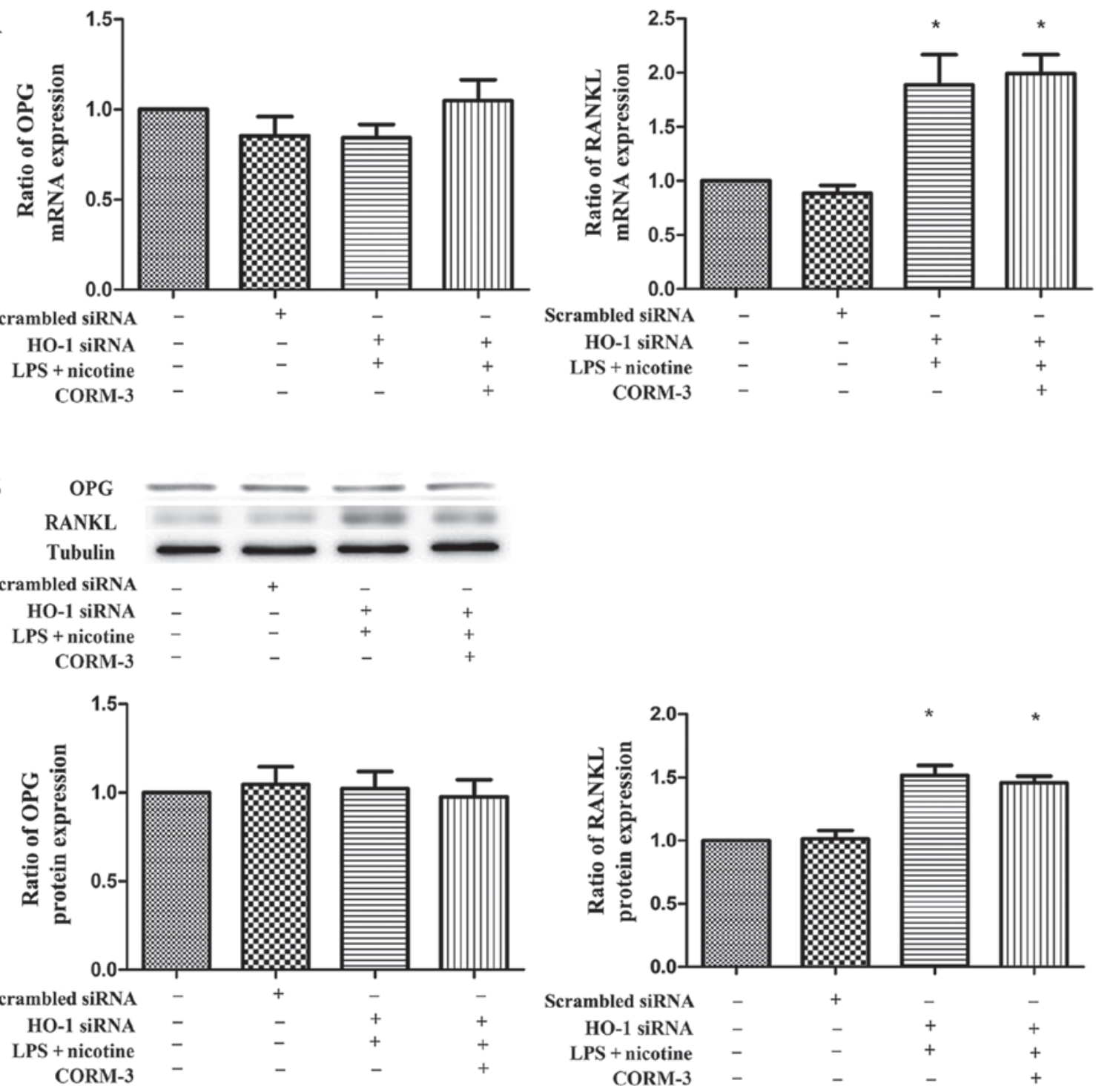

C
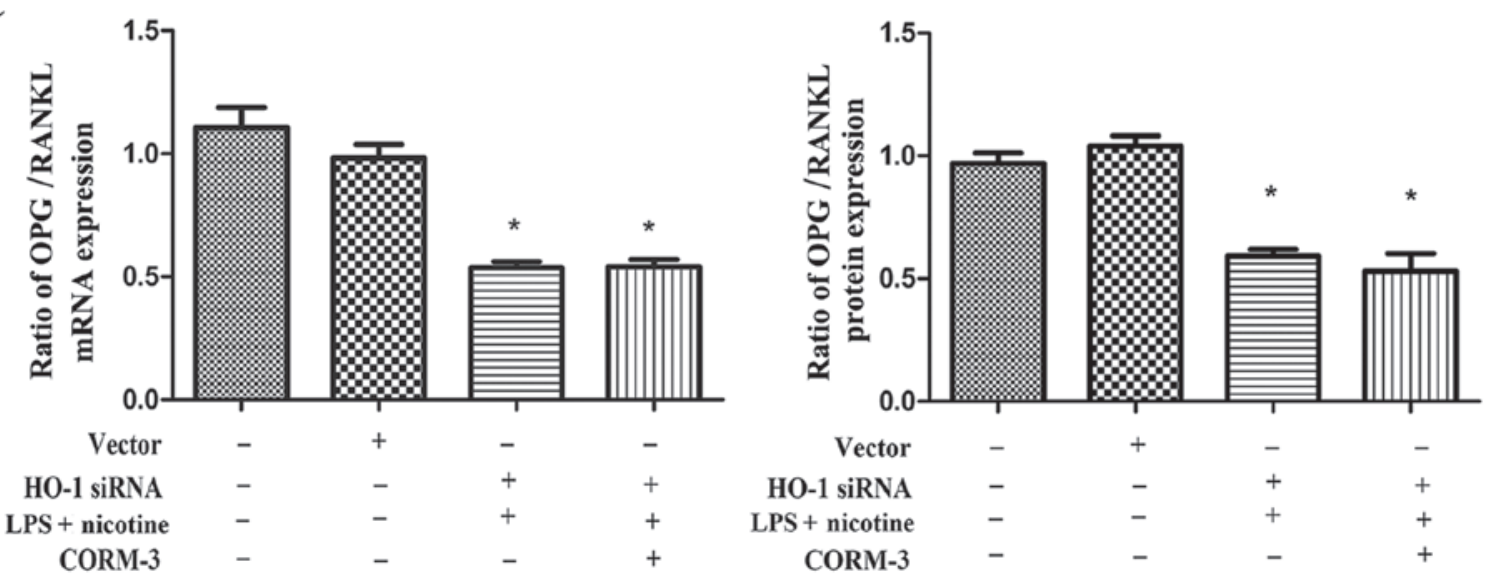

Figure 8. OPG and RANKL expression in human periodontal ligament cells stimulated with LPS and nicotine following HO-1 siRNA transfection. (A) Cells were divided into four groups as follows: Control; scrambled siRNA control, in which cells were transiently transfected with scrambled siRNA; HO-1 siRNA + LPS + nicotine group, in which cells were transiently transfected with HO-1 siRNA prior to incubation with LPS (1 $\mu \mathrm{g} / \mathrm{ml})$ and nicotine (5 mM); and HO-1 siRNA + CORM-3 + LPS + nicotine, in which cells transiently transfected with HO-1 siRNA were treated with CORM-3 (400 $\mu \mathrm{M})$ for $6 \mathrm{~h}$ prior to LPS and nicotine. PG and RANKL mRNA expression levels were determined by reverse transcription-quantitative polymerase chain reaction. (B) OPG and RANKL protein expression levels were determined by western blotting. (C) OPG/RANKL protein expression ratio. Tubulin was used to demonstrate equal sample loading. Results of a representative experiment are depicted. A total of three experiments was performed. "P<0.05 vs. the control group. OPG, osteoprotegerin; RANKL, receptor activator of nuclear factor-kB ligand; LPS, lipopolysaccharide; HO-1, heme oxygenase-1; siRNA, small interfering RNA; CORM, carbon monoxide-releasing molecule. 
therapeutic value for the treatment of periodontitis resulting from dental plaque and smoking.

\section{Acknowledgements}

This study was supported by the Shandong Province Natural Science (grant no. ZR2015HM019), the Jinan College and University Science and Technology Innovation Program (grant no. 201401259) and the Special Funds for Education and Awards of Shandong Province (grant no. 2014-94).

\section{References}

1. Listgarten MA: Bacteria and periodontitis. J Can Dent Assoc 62: 12-13, 1996.

2. Sanz M and van Winkelhoff AJ; Working Group 1 of Seventh European Workshop on Periodontology: Periodontal infections: Understanding the complexity - consensus of the Seventh European Workshop on Periodontology. J Clin Periodontol 38 (Suppl 11): 3-6, 2011.

3. Socransky SS and Haffajee AD: The bacterial etiology of destructive periodontal disease: Current concepts. J Periodontol 63 (Suppl 4): 322-331, 1992.

4. Yamaji Y, Kubota T, Sasaguri K, Sato S, Suzuki Y, Kumada H and Umemoto T: Inflammatory cytokine gene expression in human periodontal ligament fibroblasts stimulated with bacterial lipopolysaccharides. Infect Immun 63: 3576-3581, 1995.

5. Holt SC, Kesavalu L, Walker S and Genco CA: Virulence factors of Porphyromonas gingivalis. Periodontol 2000 20: 168-238, 1999

6. Slots J and Listgarten MA: Bacteroides gingivalis, Bacteroides intermedius and Actinobacillus actinomycetemcomitans in human periodontal diseases. J Clin Periodontol 15: 85-93, 1988.

7. Graves DT and Cochran D: The contribution of interleukin-1 and tumor necrosis factor to periodontal tissue destruction. J Periodontol 74: 391-401, 2003.

8. Offenbacher S, Heasman PA and Collins JG: Modulation of host $\mathrm{PGE}_{2}$ secretion as a determinant of periodontal disease expression. J Periodontol 64 (Suppl 5): 432-444, 1993.

9. Fukushima H, Jimi E, Okamoto F, Motokawa W and Okabe K: IL-1-induced receptor activator of NF-kappa B ligand in human periodontal ligament cells involves ERK-dependent $\mathrm{PGE}_{2}$ production. Bone 36: 267-275, 2005

10. Shimizu N, Ozawa Y, Yamaguchi M, Goseki T, Ohzeki K and Abiko Y: Induction of COX-2 expression by mechanical tension force in human periodontal ligament cells. J Periodontol 69: 670-677, 1998

11. Offenbacher S, Odle BM, Gray RC and Van Dyke TE: Crevicular fluid prostaglandin E levels as a measure of the periodontal disease status of adult and juvenile periodontitis patients. J Periodontal Res 19: 1-13, 1984

12. Offenbacher S, Odle BM and Van Dyke TE: The use of crevicular fluid prostaglandin $\mathrm{E}_{2}$ levels as a predictor of periodontal attachment loss. J Periodontal Res 21: 101-112, 1986.

13. McGuire JR, McQuade MJ, Rossmann JA, Garnick JJ, Sutherland DE, Scheidt MJ and Van Dyke TE: Cotinine in saliva and gingival crevicular fluid of smokers with periodontal disease. J Periodontol 60: 176-181, 1989.

14. Tanur E, McQuade MJ, McPherson JC, Al-Hashimi IH and Rivera-Hidalgo F: Effects of nicotine on the strength of attachment of gingival fibroblasts to glass and non-diseased human root surfaces. J Periodontol 71: 717-722, 2000.

15. Krishnan V and Davidovitch Z: Cellular, molecular, and tissuelevel reactions to orthodontic force. Am J Orthod Dentofacial Orthop 129: 469.e1-469.e32, 2006.

16. Panahian N, Yoshiura M and Maines MD: Overexpression of heme oxygenase-1 is neuroprotective in a model of permanent middle cerebral artery occlusion in transgenic mice. J Neurochem 72 : $1187-1203,1999$

17. Llesuy SF and Tomaro ML: Heme oxygenase and oxidative stress. Evidence of involvement of bilirubin as physiological protector against oxidative damage. Biochim Biophys Acta 1223: 9-14, 1994.

18. Poss KD and Tonegawa S: Heme oxygenase 1 is required for mammalian iron reutilization. Proc Natl Acad Sci USA 94: 10919-10924, 1997.
19. Pi SH, Jeong GS, Oh HW, Kim YS, Pae HO, Chung HT, Lee SK and Kim EC: Heme oxygenase-1 mediates nicotine- and lipopolysaccharide-induced expression of cyclooxygenase- 2 and inducible nitric oxide synthase in human periodontal ligament cells. J Periodontal Res 45: 177-183, 2010.

20. Otterbein LE, Bach FH, Alam J, Soares M, Tao Lu H, Wysk M, Davis RJ, Flavell RA and Choi AM: Carbon monoxide has antiinflammatory effects involving the mitogen-activated protein kinase pathway. Nat Med 6: 422-428, 2000.

21. Sethi JM, Otterbein LE and Choi AM: Differential modulation by exogenous carbon monoxide of TNF-alpha stimulated mitogenactivated protein kinases in rat pulmonary artery endothelial cells. Antioxid Redox Signal 4: 241-248, 2002.

22. Motterlini R, Clark JE, Foresti R, Sarathchandra P, Mann BE and Green CJ: Carbon monoxide-releasing molecules: Characterization of biochemical and vascular activities. Circ Res 90: E17-E24, 2002.

23. Alcaraz MJ, Guillen MI, Ferrandiz ML, Megías J and Motterlini R: Carbon monoxide-releasing molecules: A pharmacological expedient to counteract inflammation. Curr Pharm Des 14: 465-472, 2008.

24. Foresti R, Hammad J, Clark JE, Johnson TR, Mann BE, Friebe A, Green CJ and Motterlini R: Vasoactive properties of CORM-3, a novel water-soluble carbon monoxide-releasing molecule. $\mathrm{Br} \mathrm{J}$ Pharmacol 142: 453-460, 2004.

25. Motterlini R: Carbon monoxide-releasing molecules (CO-RMs): Vasodilatory, anti-ischaemic and anti-inflammatory activities. Biochem Soc Trans 35: 1142-1146, 2007.

26. Song H, Bergstrasser C, Rafat N, Höger S, Schmidt M, Endres N, Goebeler M, Hillebrands JL, Brigelius-Flohé R, Banning A, et al: The carbon monoxide releasing molecule (CORM-3) inhibits expression of vascular cell adhesion molecule- 1 and E-selectin independently of haem oxygenase-1 expression. Br J Pharmacol 157: 769-780, 2009.

27. Livak KJ and Schmittgen TD: Analysis of relative gene expression data using real-time quantitative PCR and the 2(-Delta Delta C(T)) method. Methods 25: 402-408, 2001.

28. Hong JY, Bae WJ, YiJK, Kim GT and KimEC: Anti-inflammatory and anti-osteoclastogenic effects of zinc finger protein A20 overexpression in human periodontal ligament cells. J Periodontal Res 51: 529-539, 2016.

29. Noguchi K, Shitashige M, Yanai M, Morita I, Nishihara T, Murota S and Ishikawa I: Prostaglandin production via induction of cyclooxygenase- 2 by human gingival fibroblasts stimulated with lipopolysaccharides. Inflammation 20: 555-568, 1996.

30. Gutiérrez-Venegas G, Maldonado-Fri'as S, Ontiveros-Granados A and Kawasaki Cárdenas P: Role of p38 in nitric oxide synthase and cyclooxygenase expression, and nitric oxide and $\mathrm{PGE}_{2}$ synthesis in human gingival fibroblasts stimulated with lipopolysaccharides. Life Sci 77: 60-73, 2005.

31. Wada N, Maeda H, Yoshimine Y and Akamine A: Lipopolysaccharide stimulates expression of osteoprotegerin and receptor activator of NF-kappa B ligand in periodontal ligament fibroblasts through the induction of interleukin-1 beta and tumor necrosis factor-alpha. Bone 35: 629-635, 2004.

32. Chang YC, Tsai CH, Yang SH, Liu CM and Chou MY: Induction of cyclooxygenase-2 mRNA and protein expression in human gingival fibroblasts stimulated with nicotine. J Periodontal Res 38: 496-501, 2003.

33. Urquhart P, Rosignoli G, Cooper D, Motterlini R and Perretti M: Carbon monoxide-releasing molecules modulate leukocyteendothelial interactions under flow. J Pharmacol Exp Ther 321: 656-662, 2007.

34. Ferrándiz ML, Maicas N, Garcia-Arnandis I, Terencio MC, Motterlini R, Devesa I, Joosten LA, van den Berg WB and Alcaraz MJ: Treatment with a CO-releasing molecule (CORM-3) reduces joint inflammation and erosion in murine collagen-induced arthritis. Ann Rheum Dis 67: 1211-1217, 2008.

35. Bae WJ, Shin MR, Kang SK, Zhang-Jun, Kim JY, Lee SC and Kim EC: HIF-2 inhibition suppresses inflammatory responses and osteoclastic differentiation in human periodontal ligament cells. J Cell Biochem 116: 1241-1255, 2015.

36. Kim YS, Shin SI, Kang KL, Chung JH, Herr Y, Bae WJ and Kim EC: Nicotine and lipopolysaccharide stimulate the production of MMPs and prostaglandin $\mathrm{E}_{2}$ by hypoxia-inducible factor-1 $\alpha$ up-regulation in human periodontal ligament cells. J Periodontal Res 47: 719-728, 2012.

37. Saito S, Ngan P, Rosol T, Saito M, Shimizu H, Shinjo N, Shanfeld J and Davidovitch Z: Involvement of PGE synthesis in the effect of intermittent pressure and interleukin-1 beta on bone resorption. J Dent Res 70: 27-33, 1991. 
38. Garlet GP, Cardoso CR, Silva TA, Ferreira BR, Avila-Campos MJ, Cunha FQ and Silva JS: Cytokine pattern determines the progression of experimental periodontal disease induced by Actinobacillus actinomycetemcomitans through the modulation of MMPs, RANKL, and their physiological inhibitors. Oral Microbiol Immunol 21: 12-20, 2006.

39. Yasuda H, Shima N, Nakagawa N, Yamaguchi K, Kinosaki M, Mochizuki S, Tomoyasu A, Yano K, Goto M, Murakami A, et al: Osteoclast differentiation factor is a ligand for osteoprotegerin/osteoclastogenesis-inhibitory factor and is identical to TRANCE/RANKL. Proc Natl Acad Sci USA 95: 3597-3602, 1998.

40. Lee TS and Chau LY: Heme oxygenase-1 mediates the antiinflammatory effect of interleukin-10 in mice. Nat Med 8: 240-246, 2002.

41. Min KS, Kwon YY, Lee HJ, Lee SK, Kang KH, Lee SK and Kim EC: Effects of proinflammatory cytokines on the expression of mineralization markers and heme oxygenase-1 in human pulp cells. J Endod 32: 39-43, 2006.
42. Min KS, Hwang YH, Ju HJ, Chang HS, Kang KH, Pi SH, Lee SK, Lee SK and Kim EC: Heme oxygenase-1 mediates cytoprotection against nitric oxide-induced cytotoxicity via the cGMP pathway in human pulp cells. Oral Surg Oral Med Oral Pathol Oral Radiol Endod 102: 803-808, 2006.

43. Pi SH, Kim SC, Kim HT, Lee HJ, Lee SK and Kim EC: Defense mechanism of heme oxygenase-1 against cytotoxic and receptor activator of nuclear factor-kappaB ligand inducing effects of hydrogen peroxide in human periodontal ligament cells J Periodontal Res 42: 331-339, 2007.

44. Lee SK, Park DY, Lee HJ, Lee J, Choi MK, Jeon BH, Jun CD, Lee SK and Kim EC: Functional interaction between nitric oxide-induced iron homeostasis and heme oxygenase- 1 in immortalized and malignant oral keratinocytes. Cancer Lett 249: 283-293, 2007. 